\title{
A cooperação em rede como fator de eficácia organizacional na gestão da coleta de resíduos sólidos domiciliares no município de Santo André
}

\section{The Cooperation Network as a Factor in Organizational Effectiveness in the Management of Solid Waste Collection in the City of Santo André}

\author{
Wanderley Adaid MUNHOZ* \\ Ademir Antonio FERREIRA**
}

\begin{abstract}
RESUMO
O objetivo deste artigo é analisar a cooperação em rede como fator de eficácia organizacional na gestão da coleta de resíduos sólidos domiciliares do município de Santo André, na região metropolitana de São Paulo. A orientação teórica do estudo se fundamenta no pressuposto de que todas as organizações públicas ou privadas atuam em rede e que a cooperação é um fator de análise para avaliar a eficácia organizacional na gestão do serviço público de coleta de resíduos sólidos domiciliares. A pesquisa é de natureza qualitativa e exploratória e foi realizada através de entrevistas abertas, com roteiro semiestruturado, junto aos atores participantes da rede de coleta de resíduos sólidos do município de Santo André, cujo nó central é a Secretaria do Meio Ambiente da Prefeitura. Pretende-se com este estudo contribuir para o aumento no conhecimento de fatores determinantes da eficácia organizacional em rede com base na Lei Federal 12.305/2010. Ao mesmo tempo, o trabalho pode contribuir para o aperfeiçoamento da gestão pública quando os projetos em desenvolvimento necessitarem do fator cooperação. Pretende contribuir também para o conhecimento acadêmico, tendo em vista o material existente e ainda incipiente sobre o tema redes, conforme preconizado na legislação sobre coleta de resíduos sólidos domiciliares. As conclusões do estudo convergem para a forte influência da cooperação entre os agentes atuantes em cada etapa do processo operacional da coleta e destinação dos resíduos e, principalmente, para a eficácia da gestão municipal relativamente a essa prestação de serviços à população.
\end{abstract}

Palavras chave: rede de negócios; cooperação; resíduos sólidos.

\footnotetext{
" Mestre em Administração (UNIP). Professor da Universidade Paulista (UNIP). E-mail: wamunhoz@msn.com

** Doutor em Administração (USP). Professor Titular do Programa de Mestrado em Administração da Universidade Paulista (UNIP) e Professor Sênior do Departamento de Administração da Faculdade de Economia, Administração e Contabilidade da Universidade de São Paulo (FEA/USP). E-mail: adeafer@gmail.com
} 


\begin{abstract}
The objective of this paper is to analyze the network cooperation as a factor of organizational effectiveness or failure in the management of domestic solid waste collection in the municipality of Santo André. The theoretical orientation of this work will be based on the assertion that all public or private organization works through network. The Cooperation will be the analysis factor of this work to evaluate the success of one public service management of domestic solid waste collection. The methodology to be used in this research refers to the study of the case of the municipality of Santo André, research that is qualitative and exploratory through open interviews with semi structured and previously developed guide to be applied in the participants of the network and also through documented research. With this study it is intended to increase knowledge of determinant factors of success in network based on the law. At the same time, the work will contribute for the improvement of public administration using the cooperation factor in its projects. It will contribute to academic improvement considering the shortage of materials about networks based on law and domestic solid waste collection. It is expected to conclude that network cooperation is the success factor in management of domestic solid waste collection in the municipality of Santo André.
\end{abstract}

Keywords: business network; cooperation; solid waste.

\section{Introdução}

A cooperação entre os agentes envolvidos no processo de gestão da coleta de lixo domiciliar é o objeto deste artigo, fruto de um trabalho de pesquisa que envolveu a administração pública do município de Santo André, a população, organizações sociocooperativas e empresas do setor, compondo uma rede de instituições atuando no desenvolvimento do processo.

O quadro de referência para se avaliar a cooperação dos agentes atuantes no processo, bem como a eficácia dos procedimentos adotados, é a Lei Federal $12.305 / 2010$, de $02 / 08 / 2010$, que instituiu a Política Nacional de Resíduos Sólidos e estabeleceu no contexto legal a responsabilidade dos órgãos públicos por essa atividade específica e pela gestão ambiental num sentido mais amplo. Assim, ao poder público cabe disciplinar e gerenciar todo o fluxo de resíduos gerados no município.

Segundo a Lei 12.305/2010, art. $3^{\circ}$, alínea XV,

resíduo sólido é o material, substância, objeto ou bem descartado resultante de atividades humanas em sociedade, a cuja destinação final se procede, se propõe proceder ou se está obrigado a proceder, nos estados sólido ou semissólido, bem como gases contidos em recipientes e líquidos cujas particularidades tornem inviável o seu lançamento na rede pública de esgotos ou em corpos d'água, ou exijam para isso soluções técnica ou economicamente inviáveis em face da melhor tecnologia disponível. (BRASIL, 2010).

O aspecto relevante da Lei 12.305/2010 se refere à necessidade de elaboração de Planos Municipais de Gestão Integrada de Resíduos Sólidos, que são condicionantes para o acesso aos recursos da União voltados para o saneamento básico. O texto da Lei 12.305/2010 especifica o conteúdo mínimo de um Plano de Gestão de Resíduos Sólidos, conforme apresentado no Quadro 1.

Esses planos devem estabelecer os empreendimentos e serviços relacionados à limpeza urbana e ao manejo de resíduos sólidos, priorizando os municípios que implantarem a coleta seletiva com a participação de cooperativas ou de outras formas de associação de coletores de materiais reutilizáveis e recicláveis formadas por pessoas físicas de baixa renda. O esclarecimento sobre as funções gerenciamento e gestão integrada são explicados da seguinte forma pela Lei:

Gerenciamento de resíduos sólidos é o conjunto de ações exercidas para organizar, planejar e executar atividades que facilitem o processo de trabalho, direta ou indiretamente, nas etapas de coleta, transporte, transbordo, tratamento e destinação final ambientalmente adequada dos rejeitos, de acordo com o plano municipal de gestão integrada de resíduos sólidos ou com plano de gerenciamento de resíduos sólidos, exigidos pela lei. (BRASIL, 2010). 

I - diagnóstico da situação dos resíduos sólidos gerados no respectivo território, contendo a origem, o volume, a caracteriza- ção dos resíduos e as formas de destinação e disposição final;
II - identificação de áreas ambientalmente adequadas para disposição final de rejeitos, observado o plano diretor de que trata o $\S 1^{\circ}$ do art. 182 da Constituição Federal e o zoneamento ambiental;
III - identificação das possibilidades de implantação de soluções consorciadas ou compartilhadas com outros Municípios, considerando, nos critérios de economia de escala, a proximidade dos locais estabelecidos e as formas de prevenção dos riscos ambientais;

IV - identificação dos resíduos sólidos e dos geradores sujeitos ao plano de gerenciamento específico nos termos do art. 20 ou a sistema de logística reversa na forma do art. 33, observadas as disposições desta Lei e de seu regulamento, bem como as normas estabelecidas pelos órgãos do Sisnama e do SNVS;

V - procedimentos operacionais e especificações mínimas a serem adotados nos serviços públicos de limpeza urbana e de manejo de resíduos sólidos, incluída a disposição final ambientalmente adequada dos rejeitos e observada a Lei $\mathrm{n}^{\circ} 11.445$, de 2007;

VI - indicadores de desempenho operacional e ambiental dos serviços públicos de limpeza urbana e de manejo de resíduos sólidos;

VII - regras para o transporte e outras etapas do gerenciamento de resíduos sólidos de que trata o art. 20, observadas as normas estabelecidas pelos órgãos do Sisnama e do SNVS e demais disposições;

VIII - definição das responsabilidades quanto à sua implementação e operacionalização, incluídas as etapas do plano de gerenciamento de resíduos sólidos a que se refere o art. 20;

IX - programas e ações de capacitação técnica para sua implementação e operacionalização;

$\mathrm{X}$ - programas e ações de educação ambiental que promovam a não geração, a redução, a reutilização e a reciclagem de resíduos sólidos;

XI - programas e ações para a participação dos grupos interessados, em especial das cooperativas ou outras formas de associação de catadores de materiais reutilizáveis e recicláveis formadas por pessoas físicas de baixa renda, se houver;

XII - mecanismos de criação de fontes de negócios, emprego e renda, e valorização dos resíduos;

XIII - sistema de cálculo dos custos da prestação dos serviços públicos de limpeza urbana e de manejo de resíduos sólidos, bem como a forma de cobrança desses serviços, observada a Lei $\mathrm{n}^{\circ} 11.445$, de 2007;

XIV - metas de redução, reutilização, coleta seletiva e reciclagem, entre outras, com vistas a reduzir a quantidade de rejeitos encaminhados para disposição final ambientalmente adequada;

XV - descrição das formas e dos limites da participação do poder público local na coleta seletiva e na logística reversa, respeitado o disposto no art. 33, e de outras ações relativas à responsabilidade compartilhada pelo ciclo de vida dos produtos;

XVI - meios a serem utilizados para o controle e a fiscalização, no âmbito local, da implementação e operacionalização dos planos de gerenciamento de resíduos sólidos de que trata o art. 20 e dos sistemas de logística reversa previstos no art. 33;

XVII - ações preventivas e corretivas a serem praticadas, incluindo programa de monitoramento;

XVIII - identificação dos passivos ambientais relacionados aos resíduos sólidos, incluindo áreas contaminadas, e respectivas medidas saneadoras;

XIX - periodicidade de sua revisão, observado prioritariamente o período de vigência do plano plurianual municipal.

FONTE: Lei Federal 12.305/2010. Elaborado pelos autores. 
Percebe-se a abrangência ditada pela Lei e de suas implicações em diferentes agentes da economia, da política, da sociedade e do meio ambiente. O trabalho irá concentrar-se nos princípios estabelecidos no Anexo 1 da Lei 12.305/2010 que devem ser seguidos pela administração pública e que se constituem em fatores determinantes da eficácia da gestão pública municipal dos resíduos sólidos domiciliares. Dos onze princípios estabelecidos por essa Lei, foi selecionado para este estudo o fator mais observado na literatura pesquisada sobre relacionamento em rede: cooperação.

A compreensão do termo cooperação em rede toma um sentido muito específico e adaptado à aplicação da rede como forma de organização entre empresas, quando se observam as características apresentadas por De Souza (1993, apud OLAVE; AMATO NETO, 2001) relativamente ao momento de transição da economia e por que se deve considerar que a intensificação das relações e da cooperação entre empresas está vinculada a uma tendência crescente da divisão do trabalho entre empresas.

Uma vez que a proposta deste estudo é a de analisar a cooperação em rede como fator de eficácia organizacional, iremos discutir o significado, o entendimento e as dificuldades de compreensão do termo cooperação. $\mathrm{O}$ interesse dessa discussão reside na necessidade de apontar e auxiliar a formulação de um roteiro que pudesse refletir um mínimo de interferência do pesquisador nas respostas dos entrevistados e permitisse orientar a análise e a percepção desse fator de maneira fiel em relação às respostas expressas pelos entrevistados. Outro fator indutor para essa necessária compreensão do termo cooperação está no fato de que vários autores, quando tentam definir redes, utilizam termos diferentes e que podem estabelecer igualdades relacionadas com as suas analogias.

O Quadro 2 apresenta a descrição dos termos mais presentes observados nos textos sobre redes e seus significados, extraídos do Dicionário da Língua Portuguesa de Aurélio Buarque de Holanda (1985).

Alguns pontos são comuns entre os termos mais utilizados para definir redes: a) ato, ação ou efeito; b) de trabalho ou construção; c) sozinho ou com mais pessoas; d) de maneira associativa; e) e que tenha implicações.

A partir dessa analogia entre os conceitos pudemos estabelecer uma definição que facilitou a elaboração de perguntas e as análises das respostas dos entrevistados: "cooperação se refere ao ato, ação ou efeito de trabalho, com uma ou mais pessoas, na construção de um bem público, onde se toma parte e que implica em trazer para si responsabilidades."

Nesse contexto e na tentativa de se conhecer a situação estratégica e operacional da cadeia referente aos resíduos sólidos, é importante o conhecimento da adequação de todos os agentes nela envolvidos.

A fundamentação teórica deste trabalho se encontra na afirmação de que as redes de empresas ao longo da história recente têm se constituído numa grande vantagem e num grande problema por oposição a outras formas de organização social. Por outro lado, as redes são formas de organizações mais flexíveis e adaptáveis, seguindo, de um modo muito eficiente, o caminho evolutivo dos esquemas sociais humanos (CASTELLS, 1999).

QUADRO 2 - DIFERENTES TERMOS RELACIONADOS À COOPERAÇÃO EM REDE.

\begin{tabular}{|c|c|c|c|}
\hline COOPERAÇÃO & COLABORAÇÃO & PARTICIPAÇÃO & ENVOLVIMENTO \\
\hline $\begin{array}{c}\text { Ato ou efeito de cooperar, } \\
\text { ou seja, operar ou obrar } \\
\text { simultaneamente, trabalhar } \\
\text { em comum, colaborar: } \\
\text { cooperar para o bem público; } \\
\text { cooperar em trabalhos em } \\
\text { equipe, ajudar auxiliar. }\end{array}$ & $\begin{array}{c}\text { Trabalhar na mesma } \\
\text { trabalho em comum com } \\
\text { uma ou mais pessoas, } \\
\text { partipação, contribuição, } \\
\text { ajuda, auxílio. }\end{array}$ & $\begin{array}{c}\text { Ato ou efeito de } \\
\text { participar, ter parte } \\
\text { em, tomar parte, } \\
\text { associar-se. }\end{array}$ & $\begin{array}{c}\text { Ato ou ação de } \\
\text { envolver-se, abarcar, } \\
\text { trazer em si, implicar, } \\
\text { importar, prender, atrair, } \\
\text { comprometer, misturar. }\end{array}$ \\
\hline
\end{tabular}

FONTE: Buarque de Holanda (1985). Elaborado pelos autores. 
Para Venturini et al. (2008), as redes interorganizacionais vêm surgindo em diferentes tipos de organizações, que passam a ver na cooperação um importante caminho para aumentar a competitividade através do compartilhamento de informações, tecnologia, recursos, oportunidades e riscos. Com isso cresce também o interesse por ganhos oriundos desse relacionamento.

\section{A cadeia de coleta e destinação de resíduos sólidos}

O desenvolvimento da cadeia de resíduos sólidos tem como consequência o desenvolvimento de mecanismos típicos de atuação em rede e dentro deles podem ser destacados os seguintes: cooperação, auxílio mútuo, interatividade, troca e coexistência. Pelo fato de serem complementares na forma organizacional, devem também ser considerados os aspectos funcional e de recursos dos participantes.

Assim, a cadeia de resíduos sólidos também se apresenta como um ambiente propício para o estudo das diferentes estratégias adotadas, principalmente pelas Prefeituras e empresas fabricantes de produtos que necessitem ser eliminados ou transformados na cadeia reversa da produção. O uso do conceito de redes na forma empresarial e na administração de negócios se justifica em função do aumento da competitividade e das crescentes exigências legais e nas normatizações que fazem com que as organizações se agrupem em sistemas de dupla característica, ou seja, atuam tanto como parceiros quanto como concorrentes, competindo num mesmo ambiente.

Em algumas empresas típicas, como é o caso dos hospitais, enquanto existe uma luta entre eles para se tornarem referência e modelo no tratamento de doenças e obtenção dos melhores resultados de saúde, também existem as necessidades de troca de informações sobre as experiências e práticas médicas voltadas não somente para os resultados de seus clientes, mas para a sociedade como um todo, principalmente com relação à gestão e ao gerenciamento dos resíduos sólidos hospitalares.

No caso das indústrias, estas possuem uma responsabilidade dentro da lei que transcende ao foco do seu negócio (core business), transformando-as em verdadeiras instituições de aprendizagem (learning organization) na procura por soluções reversíveis com relação aos produtos por elas desenvolvidos.

Ao cidadão cabe uma mudança de valores e comportamentos que devem ser canalizados pelo desenvolvimento de processos educacionais contemplados dentro da cadeia como um modo de redução de resíduos disponíveis ou pela destinação adequada dos mesmos. São ações conjuntas dentro da cadeia. O grau de interação entre as corporações, os órgãos oficiais e as manifestações sociais irá determinar o nível de atendimento das exigências ambientais relacionadas com os cuidados necessários no fluxo da cadeia reversa e também, o nível de competição existente entre eles.

\subsection{Logística reversa}

A logística reversa é entendida, segundo o texto da Lei 12.305/2010, como "um instrumento econômico e social caracterizado por um conjunto de ações, procedimentos e meios destinados a viabilizar a coleta e a restituição dos resíduos sólidos ao setor empresarial, para reaproveitamento, em seu ciclo ou em outros ciclos produtivos (como matéria-prima), ou outra destinação final ambientalmente correta". (BRASIL, 2010).

Além do aspecto legal, a grande preocupação com a logística reversa nos dias atuais é função direta da grande quantidade e variedade de produtos que chegam ao mercado para atender às necessidades tanto das empresas quanto dos consumidores finais. Complexos sistemas logísticos de distribuição e controle tiveram que ser desenvolvidos - embora não com a mesma velocidade da "produção" - para atender à demanda crescente da sociedade no transporte, armazenamento, tratamento e destinação dessa matéria pós-consumo, além de tecnologias de transformação de produtos.

Como consequência, a questão do desenvolvimento da logística reversa deixou de ser um problema da área operacional para se transformar em uma solução da área estratégica das empresas e despertou o sentimento de sustentabilidade ambiental provocado pela visibilidade progressiva dos excessos de descartes in natura no meio ambiente. 
Leite (2009) observa que o escopo da logística reversa tem sido ampliado para além de operações logísticas de retorno de produtos de pós-venda e de pós-consumo e que se torna um instrumento de competitividade empresarial, quando sua atuação:

- é utilizada sob a forma de agregação de valor econômico;

- é voltada para a obediência a legislações;

- é utilizada como reforço de marca ou imagem institucional, e

- proporciona uma nova visão de relações entre empresas, governo e sociedade.

$\mathrm{O}$ esquema da Figura 1 procura refletir sobre o processo da logística reversa no caso de resíduos sólidos, de acordo com os parâmetros da Lei 12.305/2010.

Esses conceitos e ideias permitem visualizar a importância da transformação da logística reversa em cadeia produtiva reversa, apresentando valores econômicos expressivos e de crescente interesse empresarial, social e ecológico. Essa visão diferenciada de se encarar os negócios a partir da cadeia produtiva reversa promove o surgimento de:

- um tipo empresarial diferente daquele existente até os tempos atuais;

- diferentes razões para a construção de um modelo de negócio;
- uma visão de inter-relações mais ampla;

- uma ampliação das estratégias corporativas;

- uma visão mais equilibrada entre os modelos de negócios com base unicamente no lucro econômico/financeiro e aqueles modelos de administração sociais, políticos e ambientais que, em geral, são de alto custo e baixo retorno.

Embora para alguns setores a cadeia logística reversa esteja razoavelmente consolidada, a grande maioria das empresas dessa cadeia apresenta alta dispersão geográfica e porte inferior ao das empresas primárias. Isso ocorre porque o retorno dos bens de pós-consumo se dá pela coleta em pontos dispersos e eles dependem de sucessivas transformações até chegar à fase de reaproveitamento em um processo de remanufatura ou reintegração do material reciclado.

Donaire (1999) observa que os modelos vigentes em nossos dias, relacionados aos processos de produção, têm sua origem na exploração da natureza, mas reconhece que essa visão exploratória vem mudando ao longo dos últimos anos. O pesquisador afirma que, enquanto no passado os administradores concentravam-se na eficiência e eficácia do processo produtivo, atualmente a visão da empresa, em relação ao meio ambiente, é muito mais complexa, pois ela é vista como uma instituição sociopolítica.

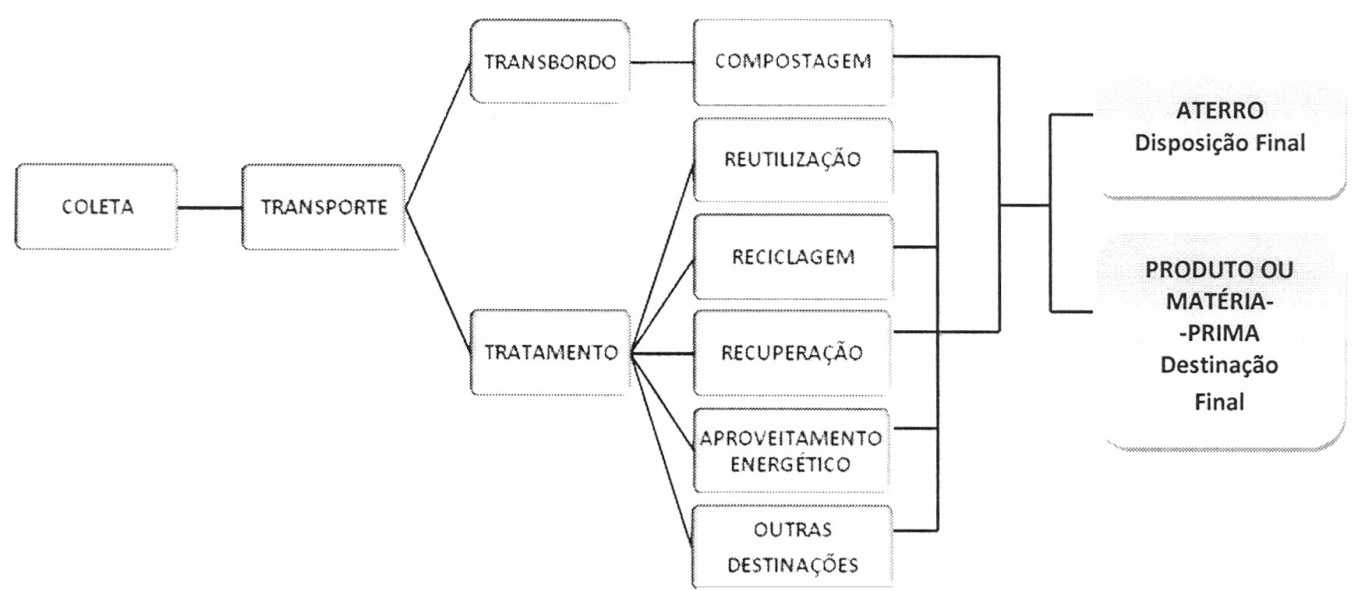

FIGURA 1 - Etapas da logística reversa de resíduos sólidos. FONTE: Lei Federal 12.305/2010. Elaborado pelos autores. 
Essa mudança de visão coloca os agentes econômicos, sociais e políticos em um ambiente de negócios um pouco nebuloso. Novas relações surgirão e trarão consigo novos processos partindo de uma relação econômica do passado para uma relação social no futuro. Assim, as questões voltadas para a qualidade de vida, preservação do meio ambiente, utilização de meios sustentáveis na produção e geração de empregos estarão presentes, paralelamente e em harmonia aos objetivos das organizações.

\section{Metodologia da pesquisa}

A estratégia que define o método de pesquisa deve atender à necessidade de se identificar dentre os diferentes métodos existentes aquele que melhor esclareça sobre a análise dos fatores do estudo (MARCONI; LAKATOS, 2007).

A escolha do método de coleta de dados deve ser criteriosa e deve atender às exigências estabelecidas em função do tipo de informação. Quando se pretende conhecer e explorar uma situação nova, não só para o pesquisador, mas também para os agentes envolvidos no processo, o estudo de caso se revela um método de pesquisa recomendado e adequado ao escopo da investigação.

Como método de pesquisa, o estudo de caso é usado, em muitas situações, para contribuir com o conhecimento de fenômenos individuais, grupais, organizacionais, sociais, políticos e relacionados (YIN, 2010). A opção pela escolha do estudo de caso ocorre quando ocorrem fatos contemporâneos, em ocasiões ou situações onde não há a possibilidade de controle ou manipulação dos comportamentos relevantes, mas onde é possível se fazer observações diretas e entrevistas sistemáticas.

Acrescentam-se também, para justificar a pertinência e adequação do método ao estudo proposto, as considerações de McClintock et al. (1983) sobre os objetivos que podem ser atingidos por um estudo de caso:

(1) capturar o esquema de referência e a definição da situação de um dado participante;

(2) permitir um exame detalhado do processo organizacional, e

(3) esclarecer aqueles fatores particulares ao caso que podem levar a um maior entendimento da causalidade.
Marconi e Lakatos (2007) citam Yin (1989, p. 19) para justificar que, apesar de ter pontos em comum com o método histórico, onde existe uma narrativa em torno de determinados fatos ou fenômenos e nos quais se evidenciam valores e padrões, o estudo de caso se caracteriza pela "capacidade de lidar com uma completa variedade de evidências: documentos, artefatos, entrevistas e observações".

Segundo Donaire (1999), para o estudo de caso são possíveis quatro tipos de delineamentos, divididos em dois grupos: o primeiro referente ao número de casos e o segundo relativo à abrangência do estudo. Assim, quanto ao número de casos podemos ter um único caso ou múltiplos casos e quanto à abrangência o estudo pode ser holístico (quando usa uma unidade de análise) ou segmentado (quando usa várias unidades de análises). Para esse pesquisador, o estudo de um único caso deve ser feito quando ele representar um caso especial, raro, revelador.

Em relação ao foco do estudo, se o caso envolve mais de uma unidade de análise, estaremos às voltas com uma pesquisa segmentada, como ocorre quando um caso único se refere a um dado programa que é constituído por vários projetos. Se isto não ocorrer e se estivermos interessados em analisar o programa em questão no seu contexto global, estaremos diante de um estudo holístico (DONAIRE, 1999).

\subsection{Campo e objeto de investigação}

O município de Santo André foi o campo de investigação escolhido porque se constitui num caso especial e revelador e atende às seguintes considerações:

- é um município de elevado índice de resíduos sólidos;

- é considerado referência nacional no processo de coleta, tratamento e destinação de resíduos sólidos; e

- está em fase de implantação de projetos para o atendimento à Lei Federal 12.305/2010.

A Figura 2 apresenta as fases do processo de coleta de resíduos sólidos domiciliares e seus agentes, tendo como referência o município de Santo André. 
A Fase 1 do processo de coleta de resíduos sólidos tem como ator principal a Prefeitura porque é ela quem cria e normatiza as ações relacionadas com a coleta e de envolvimento dos outros atores da rede. É o gestor dos processos e responsável pela governança da rede.

$\mathrm{Na}$ Fase 2, percebe-se a participação de outros três atores. A Concessionária é aquele que executa os serviços relacionados aos transportes da coleta e seus processos gerenciais, destinação e disposição dos resíduos sólidos domiciliares. Sua contratação é feita com base em licitação pública e o relacionamento é de longo prazo (5 anos) mediante contrato formal de concessão de prestação de serviços públicos com Prefeitura.

A Cooperativa tem a responsabilidade de receber os resíduos sólidos vindos da coleta seletiva, efetuar a triagem dos resíduos, separar, dispor e vender os materiais para a sua destinação dentro da cadeia logística reversa. No município de Santo André existem duas cooperativas que estão instaladas no aterro sanitário em área específica para o desenvolvimento de suas atividades, mediante um contrato de concessão de uso de local público. Foram selecionadas por atenderem aos critérios estabelecidos pela Prefeitura referentes à política de emprego de mão de obra e desenvolvimento de atividades de elevado valor social. Administram o seu negócio de forma autônoma e o contrato de concessão das instalações municipais tem a duração de dois anos.

O munícipe é o que tem a função mais simples, mas a mais importante. Mais simples porque lhe cabe apenas a separação, acondicionamento e disponibilização dos resíduos sólidos domiciliares para a coleta, e mais importante porque o início da cadeia produtiva reversa nasce de suas ações. Os volumes a serem produzidos por essa ação irão ditar uma série de outros processos, investimentos e ações para fazer a cadeia produtiva reversa funcionar. Os Postos Voluntários de Entrega, as Estações de Coleta e os Coletores Públicos não são atores porque não realizam ações, mas são soluções que complementam a coleta seletiva domiciliar.

Na Fase 3, existem outros atores que estão na continuidade da cadeia produtiva reversa e estão relacionados com a destinação (empresas que reutilizam ou transformam os resíduos) ou participam da disposição final dos resíduos nos aterros controlados.

\subsection{O processo de obtenção das informações}

Martins (2008) argumenta que para se compor a plataforma teórica de um estudo de caso, ou qualquer outra estratégia de investigação, além da pesquisa bibliográfica - levantamento de referências expostas em meios escritos ou outros meios - deve ser conduzida uma pesquisa documental, que se assemelha à pesquisa bibliográfica, mas não consiste na seleção de material editado (livros, periódicos etc.), mas busca material que não foi editado, como cartas, memorandos, correspondências, avisos, agendas, propostas, relatórios, estudos e avaliações. Ainda segundo Martins (2008), para a condução de um estudo de caso a realização de pesquisa documental é necessária para um melhor entendimento do caso e também para corroborar evidências coletadas por outros instrumentos e outras fontes, possibilitando a confiabilidade de achados através de triangulações de dados e de resultados.

Neste trabalho, a utilização da pesquisa documental foi acentuada para suportar a coleta de dados primários, tendo em vista a necessidade de conhecer a eficácia da cooperação no desempenho de uma rede em trabalhos já divulgados, assim como sob a ótica de cada um dos elementos participantes da rede em estudo, mediante análise dos documentos apresentados durante a realização das entrevistas.

As entrevistas foram realizadas com pessoal de nível gerencial da Secretaria do Meio Ambiente da Prefeitura de Santo André, da Cooperativa Cidade Limpa e da Empresa Peralta. Na Prefeitura de Santo André, foram entrevistados o Assistente de Direção da SMA, o Gerente Técnico de Coleta, o Gerente de Cooperativas e o Fiscal das Estações de Coleta. Na Cooperativa foram entrevistados os Gerentes Administrativo e Financeiro e na Concessionária foram entrevistados o Gestor de Transportes e o Consultor Técnico. Foram realizadas, também, três entrevistas com moradores de condomínio residencial e de moradia isolada. Ao todo, foram realizadas 11 entrevistas com os diferentes atores participantes do ciclo que orienta e faz movimentar a cadeia logística reversa dos resíduos sólidos residenciais..

As análises seguiram um padrão de identificação do conjunto de informações registradas em cada uma das 


\section{FASE 1}

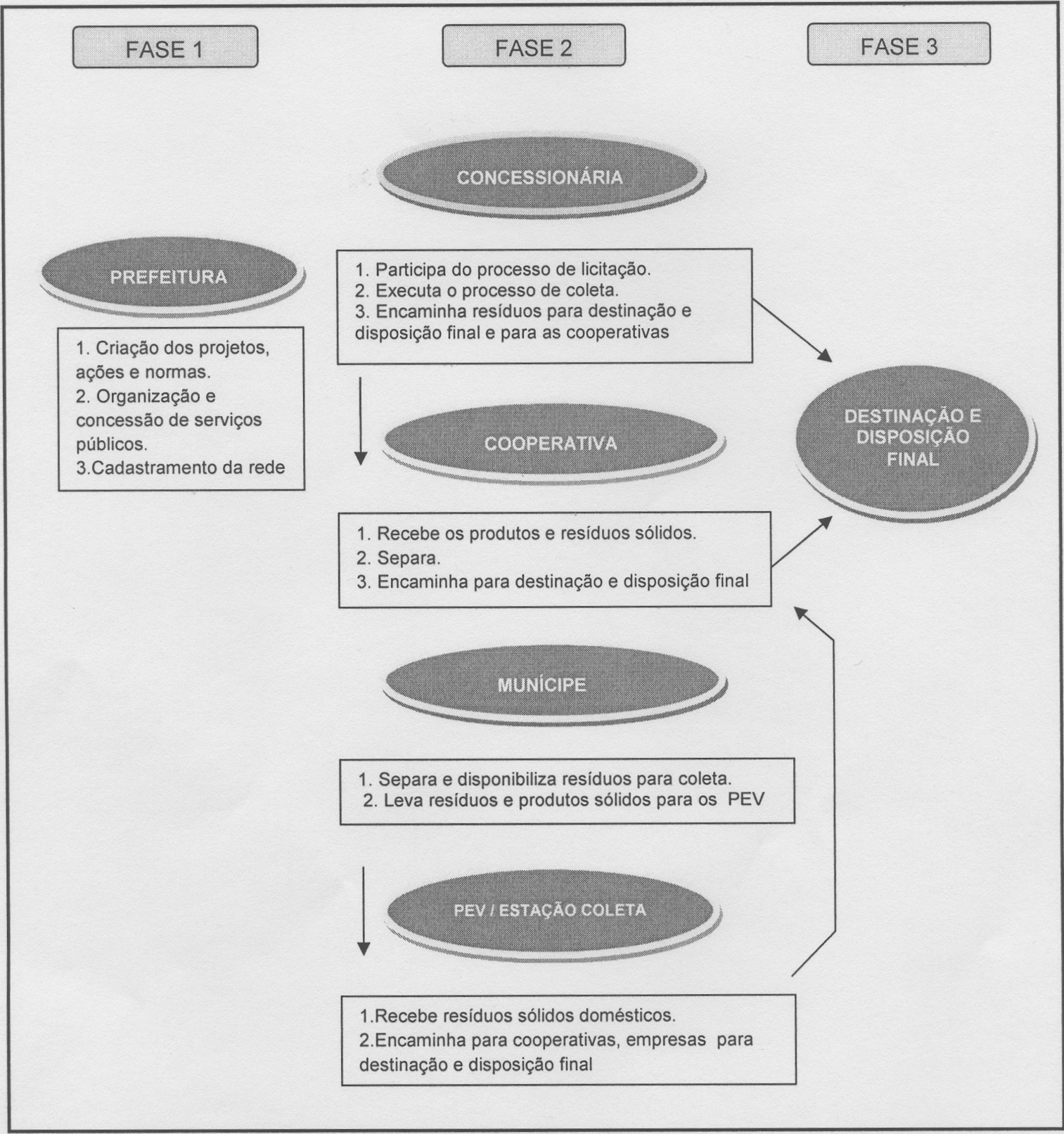

FIGURA 2 - Fases do processo de coleta de resíduos sólidos domiciliares.

FONTE: Elaborada pelos autores. 
entrevistas realizadas e que podiam caracterizar a existência da cooperação entre os atores envolvidos na coleta de resíduos sólidos domiciliares em Santo André. Assim, o conteúdo de cada relatório de entrevista foi explorado em cada termo ou expressão que identificasse a cooperação percebida pelo entrevistado. O padrão seguido está contido na definição de cooperação originada do quadro 2: "ato, ação ou efeito de trabalho, com uma ou mais pessoas, na construção de um bem público, onde se toma parte e que implique trazer para si responsabilidades."

\section{Análise das entrevistas}

A compreensão e a identificação do fator cooperação em rede para a eficácia organizacional passam, necessariamente, pela análise dos processos que constituem o sistema de gestão da coleta de resíduos sólidos domiciliares de Santo André. Assim, cada ator da rede é apresentado como um subsistema em que se procurou identificar as operações realizadas ou decisões tomadas e os resultados decorrentes ou o produto do processamento no âmbito de atuação de cada um. Isso permitiu que se avaliasse o fator cooperação tendo em vista a definição adotada, os padrões de cooperação estabelecidos e comparados com os identificados nas entrevistas.

\subsection{A Prefeitura do Município de Santo André}

$\mathrm{O}$ ator centralizador do processo e o gestor principal da cadeia logística, a Prefeitura, através da Secretaria do Meio Ambiente, recebe a maioria das demandas legais, sociais e econômicas do ciclo.

Sua responsabilidade está em interpretar as exigências legais e canalizar as necessidades relacionadas com a redução da quantidade de resíduos, com a separação dos materiais recicláveis, com a disposição e destinação final dos resíduos e, de acordo com as disposições legais, compartilhar a responsabilidade com os outros agentes do processo, conforme estabelecido no Plano Municipal de Gestão Integrada de Resíduos Sólidos.

Até agosto de 2012, os Planos Municipais Integrados de Gestão já deveriam estar concluídos e esperava-se que, ao longo do tempo, algumas questões relacionadas às responsabilidades compartilhadas fossem esclarecidas, uma vez que a implantação e consolidação do Plano deverão acontecer em um prazo mais longo.

Mas, a participação da Prefeitura vai além das suas responsabilidades estabelecidas em lei. Algumas das ações relacionadas com a cooperação foram relatadas nas entrevistas e puderam ser observadas pelo pesquisador:

- o investimento continuado em equipamentos para as cooperativas;

- a disponibilização de recursos patrimoniais para as estações de coleta;

- a disponibilização de pessoal capacitado da SMA de Santo André para gerir a cadeia;

- a disposição em unir pessoas, empresas e setores diversos da sociedade para a solução de problemas comuns;

- a transparência das ações e resultados obtidos, e

- a constância de suas ações na busca por resultados melhores.

A análise das ações da Prefeitura revela, mediante os depoimentos dos entrevistados, a necessidade da ampliação, principal e prioritariamente, de projetos que visem ao treinamento de lideranças relacionadas com a coleta seletiva e dentre elas pode-se citar os síndicos dos condomínios, pois estes são multiplicadores de ações colaborativas e referenciais na condução e implantação de procedimentos. As ações efetivas e diretas destinadas aos munícipes se utilizam de diferentes meios de comunicação: telefone, e-mail, cartas, reuniões condominiais, jornais, volantes, agentes comunitários etc.. As ações junto às Cooperativas visam incrementar a participação dos cooperados em projetos de treinamento e noções de empreendedorismo para a evolução da capacitação desses atores como alternativa para a inserção dos mesmos na solução de problemas e formulação das políticas econômico-sociais.

\subsection{Cooperativas}

As Cooperativas recebem os materiais de duas fontes básicas de origem residencial: os materiais coletados diretamente das residências por meio da coleta seletiva e os materiais entregues pela Concessionária que são frutos das entregas feitas pelos munícipes junto às 
estações de coleta. Essas duas ações são características de entrega voluntária e, por consequência, nascidas com base na cooperação.

A existência da cooperação em rede propicia a eficácia organizacional na gestão da coleta de resíduos sólidos considerando-se os seguintes aspectos:

- retira-se do meio ambiente material poluente que custaria muito mais caro retirá-lo de outros locais, caso não houvesse a ação de cooperação espontânea;

- eleva o sentimento de cidadania do munícipe, fazendo com que ele seja mais participativo dos desígnios de sua cidade;

- melhora as condições de vida daquelas pessoas que: a) são excluídas do mercado de trabalho; b) possuem baixa qualificação; c) têm interesse em se desenvolver através de novas oportunidades derivadas da coleta seletiva; e d) necessitam de renda principal ou complementar;

- proporciona a recuperação de matérias-primas para a reinserção na cadeia produtiva;

- fortalece a instituição cooperativa pelo valor agregado e gerado através dos processos de triagem, separação, acondicionamento e distribuição aos outros elos da cadeia logística reversa.

A instituição cooperativa significa o trabalho comunitário que tem como sustentação filosófica a cooperação entre seus componentes. Seu conceito social e econômico pode ser expandido para toda a sociedade As entrevistas realizadas mostram que esse modelo organizacional, embora exista há tempos na malha social e econômica, precisa de forte revitalização para continuar agregando valor em sua atuação e servir como evolução de modelo organizacional com fortes características de organização em rede.

\subsection{Concessionárias}

As Concessionárias desempenham um papel de menor intensidade na cooperação dentro da rede. A sua participação se caracteriza como uma atividade empresarial e econômica, embora a responsabilidade social esteja presente na essência do trabalho realizado e nos contratos de concessão do serviço público. Entretanto, conforme relatado pelos entrevistados da Prefeitura e das Cooperativas, as Concessionárias também colaboram nas demandas urgentes e eventuais do processo.

Essa cooperação relaciona-se com a entrega dos resíduos sólidos, principalmente daqueles advindos das estações de coleta, para as Cooperativas ou para as empresas que irão transformar esses materiais. Os resíduos recicláveis servem para o abastecimento da cadeia logística reversa e, como em todo processo produtivo, existem demandas e por vezes essas demandas são urgentes. É nesse momento que é solicitado à concessionária o abastecimento das empresas que fazem parte da rede em seus diferentes níveis e elas contam com esse atendimento colaborativo, que refere-se à captação mais rápida dos resíduos sólidos secos recicláveis, ao auxílio no descarregamento dos veículos e caçambas e ao prolongamento do horário de trabalho por parte de seus funcionários colaboradores. A cooperação também foi observada com relação ao cumprimento rigoroso de suas atividades e compromissos contratuais. As concessionárias sempre foram citadas positivamente quanto aos horários, forma e cuidado com que coletam e entregam o material reciclável.

\subsection{Munícipes}

O munícipe é o responsável por iniciar o processo de coleta seletiva dos resíduos sólidos. É uma atividade que exige mais trabalho, discernimento, consciência, atitude, organização e disposição para a sua execução. Embora as ações de orientação, comunicação e a disponibilização de canais de acesso sejam oferecidas pela Prefeitura, sua eficácia no processo de gestão da coleta de resíduos sólidos domiciliares é reduzida.

As entrevistas realizadas mostraram que as gerações mais novas são mais sensíveis a essas propostas, provavelmente porque todo o processo de educação ambiental é recente e foi incorporado nas escolas há poucos anos. As gerações antigas são mais resistentes às mudanças de hábitos e estão menos comprometidas com os aspectos ambientais no sentido do reconhecimento da importância de suas ações. Foi comum ouvir nas entrevistas pais que afirmaram que seus filhos pequenos 
aprendem nas escolas os novos comportamentos e os transferem para os pais.

A entrevista com o síndico de condomínio residencial revelou que os condôminos são instruídos para realizar habitualmente os procedimentos de separação dos resíduos sólidos úmidos e secos para a coleta, mas não pôde afirmar se o conteúdo dessa separação em sacos diferentes entre os úmidos e secos é adequado ou não. Informou também que condomínio procura dar treinamento aos seus funcionários sobre a execução desses procedimentos de coleta interna e disposição para a coleta externa.

O entrevistado reconhece a cooperação da Prefeitu$\mathrm{ra}$, pois atendeu prontamente às suas solicitações e tomou as providências necessárias para a solução das demandas que foram apresentadas quando da necessidade de troca do recipiente que armazena os resíduos sólidos secos recicláveis. Por outro lado, afirma nunca ter recebido qualquer tipo de orientação técnica da Prefeitura, mas que gostaria muito de tê-la.

A entrevista com uma moradora do condomínio mostra que existe a preocupação da Prefeitura em informar e comunicar os munícipes sobre as suas ações relacionadas com a coleta seletiva, apresentando a disponibilização dos seus serviços com dia, local e hora marcados através de telefonemas e abordagens escritas. A entrevistada, embora afirme que tenha recebido orientação por parte da Prefeitura, reconhece que a população em geral não participa mais da coleta seletiva por falta de orientação e informação sobre o destino dos materiais.

$\mathrm{O}$ entrevistado morador de residência autônoma percebe a existência de folhetos de comunicação, mas não relaciona as informações de coleta ali inseridas como necessárias para a sua melhor inserção no processo. Identifica a existência de caçambas colocadas pela Prefeitura a dois quarteirões de sua residência, mas não reconhece claramente esse esforço. Deduz-se que o processo de divulgação, transferência de informação e formação de conceitos relacionados à eficácia na coleta de resíduos sólidos domiciliares é necessário e relevante. Paradoxalmente, o pesquisador observou que o entrevistado tinha um carrinho de mão repleto de garrafas plásticas usadas, as quais seriam destinadas a um amigo que as iria utilizar para envasar os produtos de limpeza que ele fabricava na sua casa. Com relação à participação dos munícipes no processo, as reclamações mais contundentes por parte das Cooperativas estão relacionadas com a mistura de resíduos secos e úmidos no mesmo saco plástico, o que impede, logicamente, o aproveitamento total ou parcial dos resíduos.

A Concessionária, no dia de coleta dos resíduos sólidos em localidades onde as residências são autônomas, ou seja, não condominiais, quando observa que os resíduos secos possuem mistura com os resíduos úmidos, deixa de fazer a coleta, prejudicando assim o processo como um todo e gerando conflitos com os moradores.

\subsection{Nivel de cooperação dos agentes}

Conforme citado anteriormente, a Lei 12.305/2010 prevê, além das disposições legais e obrigatórias, as ações de cooperação entre os agentes envolvidos no processo.

O Quadro 3 mostra um resumo das ações de cooperação que são esperadas na coleta seletiva de resíduos sólidos, de acordo com a redação oferecida pela lei.

O resultado dessa análise ofereceu um quadro de referência do grau de cooperação entre os agentes, em três níveis:

- um nível baixo é aquele onde o ator realiza poucas ações para a melhoria do sistema de coleta e os outros agentes têm várias reclamações em função de sua participação colaborativa, embora possua posição determinante no sucesso da gestão de coleta de resíduos. Além desses aspectos, ele demonstra baixo envolvimento e possui atitudes conformistas;

- um nível médio, onde aparecem algumas ações que melhoram o sistema e as reclamações não são fortes. O agente possui razoável conhecimento sobre o funcionamento do sistema de coleta seletiva e de sua posição na rede, entretanto, suas ações são abaixo do esperado;

- um nível alto de cooperação, que pode ser observado na quantidade de ações que o agente realiza e serve como referência do sistema de coleta na questão da organização. Em geral, é proativo e conhece o sistema por inteiro. 
QUADRO 3 - ANÁLISE DA COOPERAÇÃO EM REDE NA COLETA DE RESÍDUOS SÓLIDOS DA PMSA.

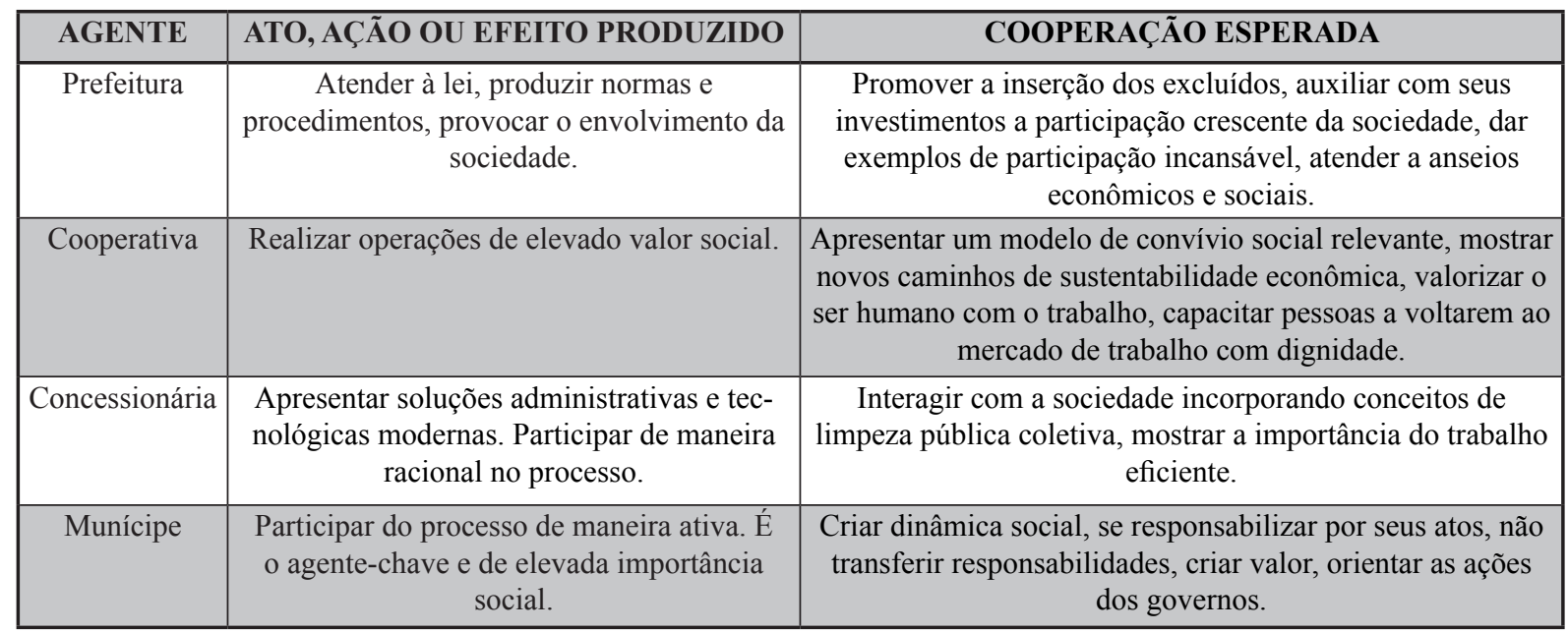

FONTE: Lei Federal 12.305/2010. Elaborado pelos autores.

A partir da análise das entrevistas realizadas e dos pressupostos de cooperação regidos pela Lei 12.305/2010 e implícitos no Plano de Gestão Integrado, foram estabelecidos os critérios para se avaliar o nível de cooperação observado entre os atores da rede. Esses critérios são empíricos e fruto do considerável volume de informações coletadas na leitura dos textos da lei e nas entrevistas realizadas.

O Quadro 4 sintetiza os critérios que foram aplicados para se avaliar o grau de cooperação de cada um dos envolvidos no processo de coleta de resíduos sólidos domiciliares do município e Santo André.

O resultado da aplicação desses critérios à análise das entrevistas realizadas permitiu que se estabelecesse o nível de cooperação de cada um dos agentes pesquisados.

O grau mais elevado de cooperação, efetivamente, foi o da Prefeitura de Santo André. As suas ações de cooperação constituem fator determinante para o funcionamento de todo o sistema de coleta. A extensão do atendimento da coleta é de $175 \mathrm{~km}^{2}$, sendo beneficiadas aproximadamente 700 mil pessoas moradoras do município, ou seja, $100 \%$ da população residente. O município possui uma malha de 573 pontos de coleta seletiva, entre estações de coleta e postos voluntários de entrega. Somente nas estações de coletas o volume total coletado ultrapassa as mil toneladas/ano, mas o dado mais significativo da eficácia organizacional é percebido na coleta domiciliar, porta a porta, que corresponde a quase quatro mil toneladas/ano, representando $60 \%$ do total coletado no município.

Conforme apontado anteriormente, a cooperação dada pela Prefeitura para a rede é elevada, entretanto, o aumento da eficácia organizacional da gestão da coleta de resíduos sólidos depende do aumento de ações voltadas aos diferentes segmentos sociais, em particular, àquelas ações que tenham como alvo os munícipes residenciais.

As cooperativas possuem grau de cooperação baixo, com perspectivas de aumento em sua ação cooperativa a partir de um envolvimento maior com ações relacionadas à expansão econômica de suas atividades e ao desenvolvimento de seus cooperados, criando uma nova função social e econômica para suas atividades. As cooperativas possuem um papel intermediário nas relações entre as fontes de coleta de resíduos sólidos secos e os destinatários que processam esses resíduos para a cadeia logística reversa.

A concessionária, por sua vez, apresenta um grau de cooperação relacionado ao cumprimento eficiente de suas obrigações contratuais e de sua cooperação em momentos de necessidade de alguns agentes mais 
QUADRO 4 - CRITÉRIOS PARA DETERMINAÇÃO DO NÍVEL DE COOPERAÇÃO ENTRE ATORES

\begin{tabular}{|c|c|}
\hline NÍVEL & CRITÉRIOS \\
\hline Baixo & $\begin{array}{l}\text { Realiza poucas ações para melhorar o sistema de coleta. } \\
\text { Recebe várias reclamações dos outros agentes. } \\
\text { Possui posição destacada na rede, mas realiza muito abaixo do esperado. } \\
\text { Apresenta baixo nível de conhecimento sobre sua importância e sobre processos e não age proativamente. } \\
\text { Conformado com sua posição, sempre espera os outros agirem. }\end{array}$ \\
\hline Médio & $\begin{array}{l}\text { Realiza algumas ações para melhorar o sistema de coleta. } \\
\text { Possui poucas reclamações dos outros agentes. } \\
\text { Possui posição relevante no sistema de coleta, mas não valoriza essa posição. } \\
\text { Apresenta razoável nível de conhecimento sobre o sistema de coleta, mas age pouco em função de suas } \\
\text { perspectivas. } \\
\text { Inconformado com sua posição, mas posiciona-se como vítima do processo, ou simplesmente realiza a } \\
\text { sua parte. }\end{array}$ \\
\hline Alto & $\begin{array}{l}\text { Realiza várias ações para melhorar o sistema de coleta. } \\
\text { É referência em organização. } \\
\text { Está sempre evoluindo sua posição na rede. } \\
\text { Conhece bem o sistema. }\end{array}$ \\
\hline
\end{tabular}

FONTE: Lei 12.305/2010 e entrevistas realizadas. Elaborado pelos autores.

distantes da rede primária. Para passar de um grau médio para outro de nível superior de cooperação, sua participação deve ser maior, principalmente nas ações que deem suporte à Prefeitura e às empresas fabricantes de produtos que gerem descartes recuperáveis na cadeia logística reversa.

Quanto aos munícipes, estes cooperam em um nível ainda considerado baixo. É provável que, ao longo dos anos, essa participação cooperativa cresça, principalmente com o acesso da população mais jovem e adaptada aos novos costumes. Os dados relacionados com a separação adequada dos resíduos sólidos domiciliares ainda são divergentes. Alguns estudiosos apontam que atualmente somente entre $5 \%$ e $10 \%$ do lixo reciclável é separado nas residências. Dessa forma, é um mercado que tem muito espaço para crescimento. Esse crescimento é dependente do aumento na cooperação dos munícipes, pois a maioria dos entrevistados aponta o munícipe como responsável pelo baixo volume e pela inadequação dos resíduos sólidos secos recicláveis descartados junto com os resíduos sólidos úmidos.

\section{Conclusões}

Durante quase vinte anos o Brasil discutiu as formas legais para regular as relações entre os vários agentes sociais, econômicos e políticos (governo, sociedade civil, empresas, associações e cooperativas) no âmbito da preservação do meio ambiente e das condições sanitárias da população referentes à coleta e à destinação de resíduos industriais e domiciliares. Esse processo culminou com a sanção pelo Presidente da República do Brasil, em agosto de 2010, da Lei 12.305/2010, que institui a Política Nacional de Resíduos Sólidos, a qual dispõe sobre os princípios, objetivos e instrumentos, bem como sobre as diretrizes relativas à gestão integrada e ao gerenciamento de resíduos sólidos, às responsabilidades dos geradores e do poder público e aos instrumentos econômicos aplicáveis como resposta às demandas emergentes da atualidade.

A Lei 12.305/2010 estabeleceu o prazo de dois anos para a apresentação do Plano Municipal de Gestão 
Integrada de Resíduos Sólidos e provocou uma revisão geral de todos os planos municipais para a sua adequação. A Prefeitura do Município de Santo André já havia avançado nesse processo, antes mesmo do instrumento legal, e serviu como um modelo de gestão adequado para se verificar e analisar os procedimentos estabelecidos na gestão de um sistema crítico do serviço público municipal.

Em todos os municípios brasileiros esses planos já foram ou estão sendo constituídos com base no estabelecimento das responsabilidades compartilhadas entre os diferentes atores da rede formada pela cadeia logística reversa dos resíduos sólidos de origem residencial. Deve ser observado que a elaboração de um Plano Municipal de Gestão Integrada de Resíduos Sólidos e o cumprimento dos dispositivos da Lei 12.305/2012 é condição essencial para que o município tenha acesso aos recursos da União.

Essa definição de responsabilidades visa minimizar o volume de resíduos sólidos e rejeitos gerados, bem como reduzir os impactos causados à saúde humana e à qualidade ambiental decorrentes do ciclo de vida dos produtos.

A pesquisa realizada focalizou a cooperação entre as organizações que compõem uma rede de negócios para desenvolver um processo de trabalho em diversas etapas, com diferentes tarefas, atribuições e objetivos em cada elo da cadeia.

Pelas entrevistas realizadas, suportadas pela observação do pesquisador e na análise documental do processo e das disposições legais que regem a atividade de coleta e destinação de resíduos sólidos no município de Santo André, pudemos verificar que:

- a cooperação percebida ocorre em diferentes níveis entre os atores dessa rede primária, ou seja, uns são mais cooperativos do que outros;

- nem todos os atores possuem a consciência de seu papel e da sua importância na rede, embora a rede esteja consolidada e o seu funcionamento burocrático e operacional exista satisfatoriamente;

- existe um acordo cooperativo que transcende ao contrato formal entre Prefeitura e Concessionárias; essa cooperação ocorre através de operações conjuntas para atendimento de demandas dos munícipes procedentes e improcedentes, as quais são resolvidas de maneira presencial, com instruções e orientações ao reclamante. Essa eficácia pode ser percebida pela abrangência total do serviço de coleta: $100 \%$ das residências são atendidas;

- são disponibilizados pela Prefeitura os locais para entrega de resíduos sólidos secos recicláveis, que compreendem 573 pontos de coleta no município;

- os munícipes podem se utilizar de diferentes acessos para o controle e para a apresentação de suas propostas e necessidades relativas ao serviço;

- a cooperação existente nas cooperativas é um esforço social relevante, pois organiza a coleta dos resíduos sólidos gerados pelos munícipes; a cooperação ainda é pequena porque não são disponibilizados corretamente os materiais recicláveis para serem coletados.

O exercício da cooperação observado na relação entre uma empresa concessionária prestadora de um serviço público com o poder público municipal fez aumentar a integração entre eles e entre os diferentes atores da rede, pois essa cooperação de base serve como referencial de conduta que tem como resultado final o atendimento social satisfatório.

O diferencial desse modelo de rede é seu surgimento tomando-se como base a legislação, diferentemente de outros modelos que surgiram por interesses econômicos (dependência de recursos) ou pelas relações sociais preexistentes. A abordagem deste trabalho sob o ponto de vista do paradigma político legal de rede não exclui os outros paradigmas econômicos e sociais, ao contrário, a eles se integra, como é o caso das cooperativas que participam do sistema.

A evolução das cooperativas e de suas ações de cooperação passa pelo aumento da participação de seus associados no desenvolvimento profissional pessoal e na disposição por diversificar os seus mercados, aproveitando o conhecimento que possuem sobre o abastecimento da cadeia reversa com insumos recuperados. Este é um tema que poderia ser mais explorado como potencial de evolução dos cooperados em termos de capacitação para o seu negócio e para a eficácia do sistema, trazendo benefícios para a gestão pública (que oferece recursos para a atividade) e para os munícipes que se dispuserem a cooperar mais ativamente. 


\section{Referências}

BRASIL. Presidência da República, Casa Civil, Subchefia para Assuntos Jurídicos. Lei Federal n. 12.305/2010. Institui a Política Nacional de Resíduos Sólidos. Diário Oficial da União de 02/08/2010. Brasília, DF, 2010.

BUARQUE DE HOLANDA, A. F. Novo Dicionário da Lingua Portuguesa. 15. ed. Rio de Janeiro: Nova Fronteira, 1975.

CASTELLS, M. A sociedade em rede. v. 1. São Paulo: Paz e Terra; 1999.

DONAIRE, D. Gestão ambiental na empresa. 2. ed. São Paulo: Atlas, 1999.

LEITE, P. R. Logística reversa: meio ambiente e competitividade. London: Pearson Prentice Hall, 2009.

MARCONI, M. A.; LAKATOS, E. M. Metodologia científica. 5. ed. São Paulo: Atlas, 2007.

MARTINS, G. A. Estudo de caso: uma estratégia de pesquisa. 2. ed. São Paulo: Atlas, 2008.
McCLINTOCK E. et al. Close relationship. New York: W.H. Freeman and Company, 1983. p. 150.

OLAVE, M. E. L.; AMATO NETO, J. Redes de cooperação produtiva: uma estratégia de competitividade e sobrevivência para pequenas e médias empresas. Gestão e Produção, UFSCar, v. 8, n. 3, p. 289-318, dez. 2001. ISSN 0104-530X.

PREFEITURA MUNICIPAL DE SANTO ANDRÉ. Secretaria de Desenvolvimento Econômico e Trabalho, Departamento de Indicadores Sociais e Econômicos, Serviço Municipal de Saneamento Ambiental. Anuário de Santo André. Publicação Oficial, 2009.

VENTURINI, J. C.; PEREIRA, B. A. D; CORRÊA, N. F., NAGE, F. de B. Assimetria de informação em redes de empresas horizontais: um estudo das diferentes percepções de seus atores. In: ENCONTRO DA ANPAD, 32., setembro de 2008. Anais... Rio de Janeiro, 2008.

YIN, R. K. Estudo de caso: planejamento e métodos. 4. ed. Porto Alegre: Bookman, 2010.

Recebido em 21 de maio de 2012.

Aceito em 28 de novembro de 2012.

Publicado em dezembro de 2012. 